\title{
ASSESSMENT OF INITIAL STROKE SEVERITY BY NATIONAL INSTITUTE HEALTH STROKE SCALE (NIHSS) SCORE AT ADMISSION
}

\author{
GHOSE SK ${ }^{1}$, AHMED KGU ${ }^{2}$, CHOWDHURY AH ${ }^{3}$, ATMH HASAN ${ }^{4}$, SAHA K ${ }^{5}$, MAHMUD R ${ }^{6}$, JOY \\ $\mathrm{NI}^{7}$, BISWAS $\mathrm{R}^{8}$, SARKAR MSR ${ }^{9}$, RAHMAN MM ${ }^{10}$, SINA $\mathrm{H}^{11}$, ARIFUZZAMAN $\mathrm{M}^{12}$, ALAM I3, \\ HOSSAIN MM ${ }^{14}$, KARIM ASMR ${ }^{15}$, HABIB $\mathrm{M}^{16}$
}

\begin{abstract}
:
Background: The National Institutes of Health Stroke Scale or NIH Stroke Scale (NIHSS) is a widely used tool for assessing stroke severity. We conducted this study to determine the severity of stroke patients admitted in a tertiary care hospital.
\end{abstract}

Methods: This is a cross sectional study conducted in Department of Neurology, Dhaka Medical College Hospital from April 2016 to October 2016 involving 91 acute stroke patients.

Result: About half (44\%) of the patients were older than 60 years of age and mean age of the patients was 60.34( \pm 16.1$)$ years at onset and there is a slight female predominance (51.6\%). Majority had hypertension (75.8\%) followed by physical inactivity (67\%), diabetes (37.4\%), smoking (33\%), obesity (23.1\%), family H/O stroke (20.9\%) and dyslipideamia (15.4\%). Many patients were found to have hyperglycemia (14.3\%) followed by hyperthermia (13.2\%), hypotension (4.4\%) and low oxygen saturation (3.3\%) at the time of admission. Most of them had ischemic stroke (60\%), followed by intracerebral hemorrhage (35\%) and subarachnoid hemorrhage (5\%). After leveling with NIHSS score more than half of the patients (51\%) were found to be moderate grade on admission. Although, there was no association between risk factors of stroke and admission NIHSS score level, significant association was found between hypoxia and admission NIHSS score severity.

Conclusion: Acute stroke patients, mostly have moderate grade of NIHSS score on admission. Hypertension, physical inactivity, diabetes, smoking, obesity, family H/O stroke and dyslipideamia are common risk factors observed among the patients which have no significant association with admission stroke severity determined by NIHSS score. There is significant association between hypoxia and admission NIHSS score severity.

J Dhaka Med Coll. 2017; 26(2) : 90-93

1. Dr. Swapon Kumar Ghose, Associate Professor of Neurology, Dhaka Medical College Hospital

2. Dr. Kazi Gias Uddin Ahmed, Associate Professor of Neurology, Dhaka Medical College Hospital

3. Dr. Ahmed Hossian Chowdhury, Associate Professor of Neurology, Dhaka Medical College Hospital

4. Dr A T M Hasibul Hasan, Registrar (Neurology), Dhaka Medical College Hospital

5. Dr. Kanol Saha, Associate Professor of Neurology, Dhaka Medical College Hospital

6. Dr Reaz Mahmud, Junior Consultant, Shorkari Kormojibi Hospital, Dhaka

7. Dr Nazmul Islam Joy, Junior Consultant, Shorkari Kormojibi Hospital, Dhaka

8. Dr Rama Biswas, Associate Consultant, Square Hospital, Dhaka

9. Dr Md Sadekur Rahman Sarkar, Assistant Professor (Current Charge), Sheikh Shahera Khatun Medical College

10. Dr Md Mahabubur Rahman, Assistant Registrar (Neurology), National Institute of Neurosciences and Hospital

11. Dr. Hashmi Sina, Assistant Professor of Neurology, Dhaka Medical College Hospital

12. Dr. Md. Arifuzzaman, Assistant Professor of Neurology, Dhaka Medical College Hospital

13. Dr Iftikher Alam, Junior Consultant, Neurology, Dhaka Medical College Hospital

14. Dr Mohammad Murad Hossain, Associate Professor (Medicine), Dhaka Medical College Hospital

15. Dr A S M Rezaul Karim, Senior Consultant (Medicine), Nilphamari Sadar Hospital, Nilphamari

16. Professor Mansur Habib, Professor \& Head of Neurology, Dhaka Medical College Hospital

Correspondence :Dr ATM Hasibul Hasan, Registrar (Neurology), DMCH. Phone-01763498663. Email:parag007us@gmail.com

Received: 21 July $2017 \quad$ Revision: 01 September 2017

Accepted: 18 September 2017

DOI: http://dx.doi.org/10.3329/jdmc.v26i2.38765 


\section{Introduction:}

Stroke is the second commonest cause of death $(9 \%)$ and a major cause of disability worldwide ${ }^{1}$. The prevalence of stroke is 3 per 1000 above the age of forty in Bangladesh ${ }^{2}$. The age adjusted annual death rate from stroke in UK is about 200 per 100,000 (12\% of all death) ${ }^{1}$. Annually 16.3 million people suffer from stroke worldwide, among which 11.2 million events occur in developing countries like ours and about 5.8 million people die of stroke each year, the two third of which occurs in developing nations ${ }^{3}$. An estimated 64.5 million stroke patients survived an acute stroke event and living with varying degree of disability ${ }^{3}$. The burden is projected to rise from 38 million DALY (Disability Adjusted Life Year) in 1990 to 61 million DALY in $2020^{4}$.

When patient-level stroke outcomes are assessed, initial stroke severity is one of the variables that must be taken into account in adjusting outcomes for differences in group of patients $^{5-6}$. This adjustment is critical, because it is well established that stroke severity at onset influences many outcomes, including mortality, length of hospital stay, type and severity of deficit, and eventual functional recovery. ${ }^{7-12}$ Although initial stroke severity can be validly assessed in prospective studies, requisite variables are not typically recorded in an established and widely accepted way in most patient care settings.

The National Institutes of Health Stroke Scale or NIH Stroke Scale (NIHSS) is a tool used by healthcare providers to objectively quantify the impairment caused by a stroke. The NIHSS is composed of 11 items, each of which scores a specific ability between a 0 and 4 . For each item, a score of 0 typically indicates normal function in that specific ability, while a higher score is indicative of some level of impairment. The individual scores from each item are summed in order to calculate a patient's total NIHSS score. The maximum possible score is 42 , with the minimum score being a 0 . The NIHSS is a well validated and commonly used stroke impairment scale that sums the scores from individual elements of the neurological examination to provide an overall stroke impairment score. ${ }^{13-14}$
Here we have tried to find out the admission severity of stroke patients with regards to NIHSS score and associated co-morbid conditions among these patients at Neurology inpatient department of Dhaka Medical College Hospital.

\section{Methods:}

This Hospital based cross sectional study was done in a total of 91 patients suffering from acute stroke admitted in neurology department of Dhaka Medical College Hospital, Dhaka from April 2016 to October 2016. We included the patients of both sexes aged 20 years or above, who had clinical sign symptoms of acute stroke admitted within 24 hours of onset and confirmed by CT scan. Patient were examined and registered in the study procedure within 24 hour of hospital admission. Patients who got admitted after 24 hours of stroke onset and those not giving any consent were excluded from the study. The stroke severity in each patient was assessed by residents in neurology who are specially trained to asses the stroke patients with NIHSS. The residents were further supervised and monitored by consultant neurologists. Semi-structured questionnaires were formed that include all the variables of interest. This questionnaire was used for collection of information by interviewing patients. No data or any information was collected without permission of the participant. Participation in this study was fully voluntary. The respondents were entirely free to withdraw their participation at any time of the study. Written informed consent was taken from each patient. Prior to consent they were explained the aim and purpose of the study. Confidentiality was assured and anonymity was maintained; no participants were identified in any report or publication under this study. After collection of information, these data were checked, verified for consistency and edited for finalized result. After editing and coding, the coded data were entered directly into the computer by using SPSS/PC software. Data cleaning validation and analysis were performed using the SPSS/PC software and graph and chart by MS excel. The results were presented in tables and graphs. Chi-square test was performed and compared at 5\% level of significance $(\mathrm{p}<0.05)$. 


\section{Results}

This study involved 91 patients aged above 20 years. About half (44\%) of the patients were elder than 60 years of age and mean age of the patients was $60.34( \pm 16.1)$ years at onset with a range of 24 to 76 years and there is a slight female predominance $(51.6 \%)$ with $M: F$ ratio of $1: 1.06$ (Table-1). While considering the distribution of risk factors, majority had hypertension (75.8\%) followed by physical inactivity (67\%), diabetes (37.4\%), smoking (33\%), obesity (23.1\%), family $\mathrm{H} / \mathrm{O}$ stroke (20.9\%) and dyslipideamia (15.4\%). Only 6.6\% were alcoholic and $4.4 \%$ had atrial fribriation (Figure-1). Many patients were found to have hyperglycemia (14.3\%) followed by hyperthermia (13.2\%), hypotension (4.4\%) and low oxygen saturation (3.3\%) at the time of admission (Figure-2). Most of them had ischemic stroke (60\%), followed by intracerebral hemorrhage $(35 \%)$ and subarachnoid hemorrhage (5\%) (Figure-3). After leveling with NIHSS score more than half of the patients (51\%) were found to be moderate grade, followed by moderate-severe (22\%), minor (16\%) and severe (11\%) (Figure-4). Though subsequent analysis did not reveal any significant association between risk factors of stroke and admission NIHSS score level (Table-2), there was significant association between hypoxia and admission NIHSS score severity (Table-3). But no association was found between hyperthermia, hypotension and hyperglycemia and admission NIHSS score level (Table-3).

\section{Discussion}

This was a hospital based observational study, done in Dhaka Medical College Hospital involving ninety one acute ischemic stroke patients. After evaluation of subjects in terms of age and gender in this study with similar studies, was observed that age and gender of patients was like other studies ${ }^{15-18}$.

The age and sex distribution of our study patients were similar to the report of Altafi D et $\mathrm{al}^{15}$.In his report $50 \%$ had hypertension, $13 \%$ diabetes, $18 \%$ hyperlipidemia, $14 \%$ a recent MI history and 31\% had smoking history. Similar to this study, Gresham et al. ${ }^{16}$ reported hypertension, hypertensive cardiovascular disease, coronary heart disease, obesity, diabetes mellitus, arthritis, left ventricular hypertrophy by ECG, and congestive heart failure as more frequent comorbidities in stroke patients.

In study of Monshi-Karimi ${ }^{17}$ results indicated that $17.4 \%$ were with hyper lipidemia, $43.5 \%$ with hypertension, $41.3 \%$ with diabetes Miletus and $45.7 \%$ were smokers. In Li study ${ }^{18} 15.2 \%$ of cases were with previous CVA history, 63.2\% with hypertension and $12.4 \%$ with diabetes history. The Atanassova study ${ }^{19}$ (NSCT) illustrated that $48.8 \%$ of patients with CVA history were smokers. Meiklejohn study 20 (Schlegel et al., 2003) showed the frequency of 6.6\% diabetes, 50\% smoking, $41.5 \%$ hypertension history, $13.2 \%$ hyperlipidemia history and $14.2 \%$ of subjects had no risk factor. Evaluation of current and other studies showed that the hypertension is one of the most prevalence of cardiovascular risk factors that this is probably due to the high prevalence of this disease in older patients. History of previous MI incidence in this study was frequent. Stöllberger study ${ }^{21}$ showed in their study that intracranial hemorrhage was more prevalent in diabetic. Schlegel study ${ }^{22}$ stated that any major complication such as infection, MI, recurrent stroke and respiratory failure leading to increased level of NIHSS and also reduced level discharge of patients possibility. The Admission severity determined by NIHSS score in our study was also similar to the report of Altafi D et $\mathrm{al}^{15}$. Like our study his analysis also could not find any significant relationship between NIHSS score category and risk factors that the patients had on admission.

There were several limitations in this study. First of all, this study measured only admission NIHSS score which was not compared with a very short term outcome of acute stroke patients during hospital stay. A long term follow up study is required for making further comments. Secondly, the sample size was relatively small and the duration of the study was short. Moreover, the study was a single center study which might not reflect the actual epidemiological and clinical picture. 


\section{Conclusion}

Acute stroke patients, who get admitted in tertiary care hospital mostly have moderate grade NIHSS score level. Hypertension, physical inactivity, diabetes, smoking, obesity, family $\mathrm{H}$ / $\mathrm{O}$ stroke and dyslipideamia are common risk factors observed among the patients which have no significant association with admission stroke severity determined by NIHSS score. There is significant association between hypoxia and admission NIHSS score severity.

\section{References:}

1. Kumar P, Clark M, Editors. Kumar \& Clark Clinical Medicine. $7^{\text {th }}$ edition. Spain: Elsevier limited; 2009: pp-1126.

2. Mohammad QD, Habib M, Hoque A, Alam B et al. Prevalence of stroke above forty years. Mymenshingh Med J 2011;20(4): 640-4.

3. Truelsen T, Bonita R. The worldwide burden of stroke: current status and future projections. In: Fisher M, editor. Handbook of Clinical Neurology, Elsevier B.V. 2009. vol 92(3 ${ }^{\text {rd }}$ series): pp-327-336.

4. Mackay J, Mensah GA. Global Burden of Stroke. In : The atlas of Heart Disease and Stroke (Part-three). World Health Organization: pp-50-51.

5. Davenport RJ, Dennis MS, Warlow CP. Effect of correcting outcome data for case mix: an example from stroke medicine. BMJ. 1996;312:1503-1505.

6. Irwin $\mathrm{P}$, Rudd $\mathrm{A}$, for the Intercollegiate Working Party for Stroke. Casemix and process indicators of outcome in stroke: the Royal College of Physicians minimum data set for stroke. J R Coll Physicians Lond. 1998;32:442- 444.

7. Oxbury JM, Breenhall RCD, Grainger KMR. Predicting the outcome of stroke: acute stage after cerebral infarction. BMJ. 1975;3:125-127.

8. Heinemann AW, Roth EJ, Cichowski K, Betts HB. Multivariate analysis of improvement and outcome following stroke rehabilitation. Arch Neurol. 1989;44:1167-1172.

9. Muir KW, Weir CJ, Murray GD, Povey C, Lees KR. Comparison of neurological scales and scoring systems for acute stroke prognosis. Stroke. 1996;27:1817-1820.

10. Westling B, Norrving B, Thorngren M. Survival following stroke: a prospective population-based study of 438 hospitalized cases with prediction according to subtype, severity and age. Acta Neurol Scand. 1990;81:457-463.
11. Samuelsson M, Soderfeldt B, Olsson GB. Functional outcome in patients with lacunar infarction. Stroke. 1996;27:842- 846.

12. DeGraba TJ, Hallenbeck JM, Pettigrew KD, Dutka AJ, Kelly BJ. Progression in acute stroke: value of the initial NIH Stroke Scale score on patient stratification in future trials. Stroke. 1999;30:1208 -1212 .

13. Brott T, Adams HP Jr, Olinger CP, Marler JR, Barsan WG, Biller J, Spilker J, Holleran R, Eberle R, Herztberg V, Rorick M, Moonaw CJ, Walker M. Measurement of acute cerebral infarction: a clinical examination scale. Stroke. 1989;20:864-870.

14. Goldstein LB, Bertels C, Davis JN. Interrater reliability of the NIH Stroke Scale. Arch Neurol. 1989;46:660-662.

15. Davar Altafi, Maryam Hosseini Khotbesara2, Mahsa Hosseini Khotbesara, Amin Bagheri. A Comparative Study OF NIHSS between Ischemic Stroke Patients with and without Risk Factors. Tech J Engin \& App Sci., 3 (17): 1954-1957, 2013.

16. Gresham GE, Phillips TF, Wolf PA, McNamara PM, Kannel WB, Dawber TR. Epidemiologic profile of longterm stroke disability: the Framingham Study. Arch Phys Med Rehabil 1979; 60: 487-491.

17. Monshi Karimi A, Mohtadi Nia J, Farhoodi M, Aref Hosseini SR. 2011. Relationship between smoking status, vitamin B12 and folic acid, with homocysteine in patients with ischemic. Stroke. 33(2):81-86.

18. Li ZH, Sun L, Zhang H, Liao Y, Wang D, Zhao B. 2003. Elevated plasma homocysteine was associated with hemorrhagic and ischemic stroke, but methylenetetrahydrofolate reductase gene C677T polymorphism was a risk factor for thrombotic stroke: a multicenter case-control study in china. Stroke.34:2085-2090.

19. Atanassova PA, Angelova E, Tzvetanov P, Semerdjieva M, Dimitrov B. 2007. Modelling of increased homocysteine ischemic stroke. Arq Neuropsiquiatr. 65(1):24-31.

20. Meiklejohn DJ, Vickers MA, Dijkhuisen R, Greaves M. 2001. Plasma homocysteine concentrations in the acute and convalescent periods of atherothrombotic. Stroke. 32(1):57-62.

21. Stöllberger C, Exner I, Finsterer J, Slany J, Steger C. 2005. Stroke in diabetic and non-diabetic patients: course and prognostic value of admission serum glucose. Ann Med. 37(5):357-64.

22. Schlegel D, Kolb SJ, Luciano JM, Tovar JM, Cucchiara BL, Liebeskind DS, Kasner SE. 2003. Utility of the NIH Stroke Scale as a predictor of hospital disposition. Stroke. 34(1):134-7. 